\title{
Physicians' Satisfaction with The Service Quality of A Clinical Laboratory in Calapan City, Oriental Mindoro
}

\author{
Gregorio L. Martin I' , Bea Florence T. Cawaling1', Danna M. Chumacera ${ }^{1}$, Jethro Lorenzo \\ G. De Guzman', Pamela Dorothy G. De Guzman'1, Fer Cedrick T. De Vera1, Florence \\ Navidad1 \\ ${ }^{1}$ Department of Medical Technology, University of Santo Tomas, Philippines
}

\begin{abstract}
Clinical laboratory service assessment is essential in improving the quality of care and guaranteeing that quality standards are achieved. Physicians are their primary clients as physicians rely extensively on laboratory findings to make reliable diagnoses. Thus, the study aimed to assess physicians' satisfaction at a clinical laboratory in Calapan City, Oriental Mindoro, Philippines, based on the quality of service they provide, by identifying which factors greatly influence physicians' satisfaction and the physicians' concerns and recommendations. The laboratory accessibility, report format, information system, turnaround time, and service provision are the five factors evaluated in this study. A mixed-method approach was utilized wherein an online survey consisting of a 5-point Likert scale, and open-ended questions were deployed using Google forms and answered by 42 physicians. IBM SPSS Statistics 22 and the MAXQDA system were used to evaluate the responses. Overall, the physicians were satisfied with the clinical laboratory's services $(X=3.9762)$. The laboratory report format has the most significant impact on physicians' overall satisfaction and is the factor with which physicians are most satisfied. Improvement of the turnaround time is advised. Future studies, including more laboratories and participants, are suggested.
\end{abstract}

Keywords: Clinical laboratories; Physician; Satisfaction; Service Quality

This is an open access article under the $\mathrm{CC}-\mathrm{BY}-\mathrm{NC}$ license

\section{INTRODUCTION}

Clinical laboratories play a vital role in the healthcare continuum. They are the most valuable sources of information in the healthcare setting and medical research (American Society for Clinical Laboratory Science, 2005). It is estimated that more than $70 \%$ of clinical decisions are based on data obtained from laboratory and pathological results (Kappelmayer \& Toth, 2016). Laboratory results containing errors have a crucial influence on the diagnosis, intervention, or prevention strategy a physician prescribes to the patient (Kaushik \& Green, 2014).

According to Zaini and Zaini (2015), physicians are the first-hand customers of clinical laboratories whose views are vital in identifying areas for improvement. Their observations and remarks can help clinical laboratories identify flaws and limitations in providing quality service, significantly proving that a good physician-laboratory relationship is important (Adulkader \& Triana, 2013).

In the Philippines, there is no national level of information or data regarding this matter. Researchers have not found studies that measure the service quality of a clinical laboratory from a physician's perspective in the country. It is in this light that the study aims to assess physicians' satisfaction in the context of how

Corresponding author

Bea Florence T. Cawaling, beaflorence.cawaling.pharma@ust.edu.ph

DOI: (to be processed)

Research Synergy Foundation 
Filipino physicians perceive a clinical laboratory in the Philippines, particularly in Calapan City, Oriental Mindoro. This study would also correlate the factors of laboratory service to physicians' satisfaction, determine the impact of laboratory's quality of service on the overall satisfaction of physicians; and, identify physicians' recommendations for future improvement.

\section{LITERATURE REVIEW}

Quality of services in healthcare in relation to customer satisfaction (Donabedian, 2005). The Donabedian model consists of three factors: the structure, process, and outcome, which would help evaluate a physician's satisfaction (Khamis \& Njau, 2014). Theories such as SERVQUAL theory and End Result theory were also used to aid in understanding the specific factors discussed in the three Donabedian categories. The SERVQUAL theory explains that service quality provided by an organization is reflected upon the perception of the customer on how well the performance meets their expectations (Direktor \& Yesilada, 2010). At the same time, Codman's End Result theory emphasizes that the success of care is based on the quality of the product (Neuhauser, 2002).

The Donabedian theory was scrutinized to bridge the aim of the two aforementioned theories. As it provides a framework for examining and evaluating service and quality of care, factors such as laboratory accessibility, report format, provision of services, turnaround time (TAT), and laboratory information system (LIS) were identified as contributing factors to service quality.

A physician satisfaction survey based on these factors can help identify the problems arising in the laboratory. Recognizing such problems will aid the laboratory in producing an improved quality of laboratory services. Additionally, the study of Giangaspero (2016) also mentioned that having a comprehensive assessment on the reliability of services and identifying the areas that need improvement will drive laboratories to strengthen their standards towards exercising greater responsibility.

\section{RESEARCH METHODOLOGY}

A mixed-methods approach was used in this study: a technique used to gather and analyze both qualitative; and quantitative information from the same population (Shorten \& Smith, 2017). The study specifically utilized a convergent research design. The researchers simultaneously collected and analyzed quantitative and qualitative data to make a coherent conclusion (Cresswell \& Plano Clark, 2017).

This was done by conducting a survey from April to May 2021 on a clinical laboratory in Calapan City, Oriental Mindoro. The quantitative method of the questionnaire is a 5-point Likert scale, with five as the highest and equates to strongly agree and one as the lowest and refers to strongly disagree. For the qualitative method, the researchers made use of open-ended questions to obtain qualitative data. Physicians rated the quality of service that the laboratory provides by evaluating the different factors that influence their satisfaction with the laboratory. The factors evaluated in this study are the laboratory accessibility, report format, LIS, TAT, and provision of services.

A purposive sampling approach was utilized in gathering respondents for the study. The researchers conducted a census to obtain the total number of physicians working in the hospital who can participate in the study and fit the research's interests. The respondents selected are licensed physicians currently working in the hospital where the chosen clinical laboratory is also located. Subjects were excluded from the study if they were not working in the selected hospital and were unlicensed. A total of 42 physicians were qualified for this study.

To ensure that all principles are applied in the study, approval from the Faculty of Pharmacy Ethics Review Board was first secured before data collection. The respondents were given a consent form which 
provided the purpose, procedure, and benefits of the study. The participants' information was kept confidential using unique codes for every participant at any point in the study.

Survey questionnaires were administered through Google forms. The data was collated and cleaned in Google sheets prior to analyzing in IBM SPSS Statistics 22 and the MAXQDA System.

\section{FINDINGS AND DISCUSSION}

Table 1. Physician satisfaction on the service quality of the laboratory

\begin{tabular}{lcccc}
\hline Factors & $\mathbf{N}$ & $\mathbf{X}$ & $\mathbf{S D}$ & Interpretation \\
\hline Laboratory & 42 & 4.3095 & 0.68993 & Strongly Agree \\
Accessibility & & 4.4702 & 0.56902 & Strongly Agree \\
Laboratory Report & 42 & & & \\
Provision of & 42 & 4.3857 & 0.59656 & Strongly Agree \\
Services & 42 & 4.1571 & 0.74577 & Agree \\
TAT & 42 & 4.1452 & 0.67434 & Agree \\
LIS &
\end{tabular}

Interpretation: 1-1.80 Strongly Disagree; 1.81-2.60 Disagree; 2.61-3.40 Neutral/ neither agree nor disagree; 3.41-4.20 agree; 4.21-5.0 Strongly Agree

Table 1 summarizes the satisfaction of the 42 physicians with the clinical laboratory service. The respondents strongly agreed $(\mathrm{x}>=4.21)$ that the clinical laboratory is accessible and provides efficient and effective laboratory reports and provision of services. Such data imply that the respondents undoubtedly favor the statements, which deem that the factors highly meet their satisfaction. Moreover, the respondents agreed $(x>=3.41)$ that the laboratory provides adequate TAT and that they are satisfied with its LIS. The result implies that the physicians are satisfied with these factors, however not to the degree of satisfaction as compared to laboratory accessibility, report, and provision of services.

Table 2. Kendall's tau test of correlation on factors affecting physician's satisfaction

\begin{tabular}{lcc}
\hline \multicolumn{3}{c}{ Kendall Tau's Coefficient } \\
\hline & Overall Satisfaction*P-value \\
\cline { 2 - 3 } Laboratory Accessibility & 0.473 & 0.003 \\
Laboratory report format & 0.4988 & 0.0002 \\
Provision of Services & 0.6079 & 0.0000 \\
TAT & 0.5334 & 0.0001 \\
LIS & 0.5796 & 0.0000 \\
\hline
\end{tabular}

Interpretation: $|\mathrm{Tb}|=0.07$ weak association; $|\mathrm{Tb}|=0.21$ medium association; $|\mathrm{Tb}|=0.35$ strong association *Significant at $\mathrm{p}$-value $<0.05$

This table depicts the relationship between the factors affecting the physicians' satisfaction and the overall satisfaction, using Kendall's Tau-b correlation. Results showed that all factors showed a strong and positive association with the overall satisfaction of physicians and are statistically significant. 
RSF Conference Series: Medical and Health Science, Vol. 1 (1), 34-41

Physicians' satisfaction with the service quality of a clinical laboratory in Calapan City, Oriental Mindoro Gregorio L. Martin I, Bea Florence T. Cawaling, Danna M. Chumacera, Jethro Lorenzo G. De Guzman, Pamela Dorothy G. De Guzman, Fer Cedrick T. De Vera

Table 3. Multiple linear regression of the service qualities of the laboratory on the overall satisfaction of physicians

\begin{tabular}{|c|c|c|c|c|c|c|}
\hline \multicolumn{7}{|c|}{ Multiple Linear Regression } \\
\hline Source & SS & $\mathrm{df}$ & MS & & & \\
\hline Residual & 5.88613467 & 37 & .159084721 & & & \\
\hline & & & & $\begin{array}{l}\text { Number of obs } \\
\text { F }(5,37) \\
\text { Prob > F } \\
\text { R-squared } \\
\text { Adj R-squared } \\
\text { Root MSE }\end{array}$ & & $\begin{array}{r}42 \\
843.72 \\
\mathbf{0 . 0 0 0 0} \\
0.9913 \\
0.9901 \\
.39885\end{array}$ \\
\hline
\end{tabular}

\begin{tabular}{lcccccc}
\hline \multicolumn{1}{c}{ Overall } & Coef. & Std. Err. & $\mathrm{t}$ & $\mathrm{P}>|\mathrm{t}|$ & \multicolumn{2}{c|}{ [95\% Conf. Interval] } \\
\hline Laboratory Accessibility & .0003156 & .142159 & 0.00 & 0.998 & -.287726 & .2883 \\
& & & & & & 572 \\
Laboratory Report & .4421486 & .1422085 & 3.11 & 0.004 & .1540068 & .7302 \\
& & & & & & 904 \\
Provision of Services & -.1098101 & .1626617 & -0.68 & 0.504 & -.439394 & .2197 \\
TAT & & & & & & 737 \\
& .2862403 & .1280809 & 2.23 & 0.032 & .0267238 & .5457 \\
LIS & & & & & & 569 \\
& .2999501 & .115237 & 2.60 & 0.013 & .0664578 & .5334 \\
& & & & & & \\
\hline
\end{tabular}

Since Kendall Tau-b correlation only determines the association of the factors towards overall patient satisfaction, multiple linear regression was also performed to individually analyze the impact of each service quality towards overall patient satisfaction, holding other factors constant. Based on the results, report format ( $\mathrm{p}$-value $=0.004)$, TAT ( $\mathrm{p}$-value $=0.032$ ), and LIS ( $\mathrm{p}$-value $=0.013$ ) significantly contribute to the overall satisfaction score as their $\mathrm{p}$-value is less than 0.05 . On the other hand, laboratory accessibility ( $p$-value $=0.098)$ and provision of services ( $p$-value $=0.504)$ do not significantly contribute to the overall satisfaction score as their $\mathrm{p}$-value is greater than 0.05 .

\section{Issues and Concerns of Physicians in the Clinical Laboratory Services}

MAXQDA Qualitative Data Analysis was used for open-ended questions to summarize their responses and generate codes for creating a frequency table and code a cloud for visualization.

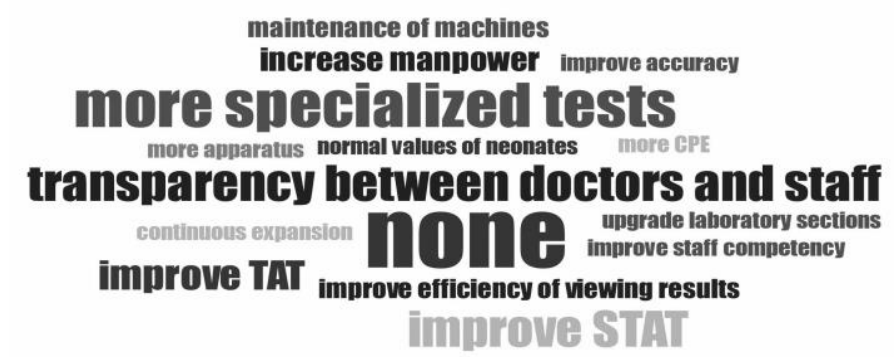

Figure 2. Word cloud for recommendations of the respondents towards the laboratory 
Table 5. Recommendations of the respondents towards the laboratory categorized according to theme

\begin{tabular}{clccc}
\hline \multicolumn{1}{c}{ Themes } & \multicolumn{1}{c}{ Recommendations } & f & $\mathbf{\%}$ & TOTAL \\
\hline No recommendations & "none" & 8 & 19.06 & $19.06 \%$ \\
Laboratory accessibility & $\begin{array}{l}\text { Transparency between doctors } \\
\text { and staff }\end{array}$ & 5 & 11.90 & $11.90 \%$ \\
Laboratory report format & Normal values for neonates & 1 & 2.38 & $16.68 \%$ \\
& More specialized tests & 6 & 14.30 & \\
Provision of services & Increase manpower & 3 & 7.14 & $26.18 \%$ \\
& Maintenance of machines & 2 & 4.76 & \\
& Improve staff competency & 1 & 2.38 & \\
& Upgrade laboratory sections & 1 & 2.38 & \\
& More apparatus & 1 & 2.38 & \\
& More CPE & 1 & 2.38 & \\
& Continuous expansion & 1 & 2.38 & \\
& Improve accuracy & 1 & 2.38 & \\
TAT & Improve TAT & 4 & 9.52 & $21.42 \%$ \\
& Improve STAT & 5 & 11.90 & \\
& Improve the efficiency of viewing & 2 & 4.76 & $4.76 \%$ \\
& results & & & \\
\hline
\end{tabular}

Table 5 displays the recommendations provided by the respondents towards the laboratory, categorized according to the themes with frequency and percentages. Most recommendations targeted the provision of services $(26.18 \%)$. The second section that demanded further attention was the turnaround time which obtained $21.42 \%$. Results also showed that $11.90 \%$ of the suggestions were focused on improving the laboratory's TAT, while $9.52 \%$ were more on the laboratory's STAT. Next in line is the laboratory report format $(16.68 \%)$ and laboratory accessibility with $11.90 \%$ The section with the least recommendations (4.76\%) is the LIS. Meanwhile, $19.06 \%$ of the respondents had no recommendations for the laboratory.

\section{Discussion}

As physicians are the primary clients of laboratories, their perceptions of the services delivered are crucial for quality service improvement of clinical laboratories. A satisfaction survey is one of the many ways where they can express their concerns about the services they have received and their opinions on what needs to be improved (Hailu et al., 2020). To assess this, the researchers utilized a questionnaire focused on five (5) laboratory service qualities: laboratory accessibility, report format, provision of services, TAT, and LIS.

According to Zaini and Zaini (2015), it is essential to establish clear and dynamic communication between the laboratory and clinicians as this is critical when dealing with ambiguous, erroneous, or missing results. Such a concept is aligned with the findings of the study. On the laboratory accessibility seen in Table 1, respondents strongly agreed that the laboratory is accessible as it is responsive and shows a clear and comprehensible line of communication between the staff and physicians. Respondents also 
strongly agreed that the service manual is convenient to use and that the request and report forms are complete and comprehensible.

Furthermore, together with its LIS, the laboratory bears significant responsibilities to the community, patients, and hospitals that its employees to achieve high-quality patient outcomes as the ability to give timely and precise results is crucial. As seen in Table 1, in which the respondents strongly agreed that the staff is professional, the laboratory results are reliable, and the laboratory has a sufficient workforce to deal with requests. The respondents also agreed that it incorporates efficient handling of requests, such as viewing laboratory results. It was also found that respondents were satisfied with the TAT of the laboratory, which entails that the laboratory provides adequate TAT.

Along with descriptive statistics, the researchers also performed additional tests to support the findings, specifically to identify the association of the factors affecting the service quality of the laboratory with physician satisfaction. Other methods utilized were Kendall's Tau-b correlation and multiple linear regression.

In Table 2, the researchers performed Kendall's Tau-b to display the correlation between the laboratory's quality of service and the overall satisfaction of the physician. Through this, the researchers were able to conclude that the factors were significant and had a direct positive correlation with the overall satisfaction of the physicians which means that they are directly proportional to each other. These results provided an additional understanding of the descriptive statistics analysis. In particular, the physicians are overall satisfied with the laboratory services because they are generally satisfied with the factors affecting the service quality of the laboratory. However, this method could not specifically identify the impact of each factor on the overall satisfaction of the physicians. For this reason, the researchers performed predictive analytics to analyze the effect of each independent variable (factors of service quality) on the overall satisfaction of the physician.

The researchers used multiple regression analysis to determine the impact of the factors on physician satisfaction. Based on the results, laboratory accessibility and provision of services do not significantly contribute to the overall satisfaction score. However, these two sections being the least concern of the physicians, should not be neglected as these factors will become significant if taken as a whole. Meanwhile, other factors such as laboratory report format, TAT, and LIS significantly contribute to the overall satisfaction score as their $p$-value is $<0.05$.

Concerning the results of descriptive statistics and Kendall Tau Correlation, the researchers concluded that the multiple linear regression method provided supplementary information--physicians are overall satisfied with the laboratory-based factors of service quality.

Furthermore, a qualitative assessment through open-ended questions was further employed to tackle concerns that might not have been addressed in the Likert scale. These open-ended questions supply researchers with a wider range of perspectives. The findings have shown that the respondents still have some negative regard toward the laboratory and some recommendations, which are further discussed.

Respondent's recommendations for the laboratory were collected and are shown in Table 5. It shows that provision of services was the section that demanded further improvement. Respondents suggest that the laboratory should address these concerns by increasing their manpower capacity, consistent calibration of machines, an improvement on staff competency and accuracy of tests, upgrading laboratory sections, more apparatus, CPE, continuous expansion as well as improving the laboratory's turnaround time. These recommendations may serve as useful information for the clinical laboratory to increase their efficiency and performance. A study conducted by Salinas et al. (2018) mentioned that the 
primary aim of the laboratory is the overall improvement of patient diagnosis by implementing laboratory testing management and efficient testing capabilities such as better utilization of results and TAT.

These results are solely based on the survey done in a clinical laboratory in Calapan City, Oriental Mindoro. This study did not take into account the problems and concerns of other clinical laboratories. As a result, only the issues of the aforementioned laboratory were presented and discussed. The researchers did not investigate other clinical laboratory issues; however, this study can serve as a foundation for current laboratory circumstances.

\section{CONCLUSION AND FURTHER RESEARCH}

Following a thorough examination of the study's findings using both quantitative and qualitative data, it can be concluded that the physicians are satisfied with the services provided by the clinical laboratory in Calapan City, Oriental Mindoro. This is reflected in the physicians' mean overall satisfaction score, which manifested as "agree" but not "strongly agree." This result signifies that the physicians are not completely satisfied with the laboratory's service quality and that the laboratory may still make necessary modifications to improve its services. This is also supported by qualitative data, in which physicians identified areas for improvement.

The physicians' satisfaction was assessed using the following determinants or factors; laboratory accessibility, laboratory report format, TAT, provision of services and LIS. Based on the results of Kendall's Tau correlation, the factors generally showed a strong correlation with physicians' satisfaction. Multiple linear regression was further performed to determine the individual impact of the factors on physician satisfaction. Among the service qualities evaluated, the laboratory report format has the greatest impact on the overall satisfaction of physicians and the factor in which physicians are most satisfied within the laboratory.

The sentiments of the physicians were also expressed through their recommendations, as giving them a voice to be heard plays a vital role in future improvement. Physicians mainly suggest that the laboratory provides more specialized tests, improves its TAT snd STAT, transparency with doctors and staff, and lack of personnel.

The physicians' satisfaction in this study was confined only to the representatives of one hospital and its laboratory. It would be more comprehensive to perform research per region in the Philippines, which includes all physicians and laboratories in every province, to better understand the circumstances and conditions that occur on a wide scale, such that a collaborative improvement may be made.

\section{REFERENCES}

Donabedian, A. (2005) 'Evaluating the quality of medical care, Milbank Quarterly, pp. 691-729. DOI: 10.1111/j.1468-0009.2005.00397.x.

Giangaspero, M. (2016) 'Laboratory Diagnosis Reliability and Quality Assurance System', Clinical Microbiology: Open Access, 05(01). DOI: 10.4172/2327-5073.1000e134.

Creswell, J \& Plano Clark, P. (2007) 'Designing and Conducting Mixed Methods Research', Australian and New Zealand Journal of Public Health, 31(4), pp. 388-388. DOI: 10.1111/j.1753-6405.2007.00096.x.

Kaushik, N. and Green, S. (2014) 'Pre-analytical errors: their impact and how to minimize them.', MLO: medical laboratory observer, 46(5).

Salinas, M. et al. (2018) 'Laboratory test inappropriateness: lessons revisited and clarified in seven questions', Journal of Laboratory and Precision Medicine, 3, pp. 34-34. DOI: 10.21037/jlpm.2018.03.10. 
Science American Society for Clinical Laboratory (2013) Value of clinical laboratory services in health care., Clinical laboratory science : journal of the American Society for Medical Technology. DOI: 10.29074/ascls.26.1.8.

Shorten, A. and Smith, J. (2017) 'Mixed methods research: Expanding the evidence base', EvidenceBased Nursing, 20(3), pp. 74-75. DOI: 10.1136/Feb-2017-102699.

Zaini, Rana and Zaini, Rania (2015) 'Physician's Satisfaction from Laboratory Services in Maternity and Children Hospital in Makkah', International Journal of Laboratory Medicine \& Research, 1(1), pp. 2-5. DOI: $10.15344 / 2455-4006 / 2015 / 101$.

Hailu, H. A., et al. (2020). Physicians' satisfaction with clinical laboratory services at public hospitals in Ethiopia: A national survey. PLoS ONE, 15(4), 1-11.

https://doi.org/10.1371/journal.pone.0232178

Kappelmayer, J., \& Tóth, J. (2016). Clinical Laboratories - Production Factories or Specialized Diagnostic Centers. Ejifcc, 27(2), 156-165. Retrieved from http://www.ncbi.nlm.nih.gov/pubmed/27683528\%0Ahttp://www.pubmedcentral.nih.gov/articlerend er.fcgi?artid=PMC4975231

Mujahed Adulkader, N., \& Garcia Triana, B. E. (2013). Physician satisfaction with hospital clinical laboratory services in Aden Governorate, Yemen, 2009. Eastern Mediterranean Health Journal,19(6),555560. https://doi.org/10.26719/2013.19.6.555

Khamis, K., \& Njau, B. (2014). Patients' level of satisfaction on quality of health care at Mwananyamala hospital in Dar es Salaam, Tanzania. BMC Health Services Research. https://doi.org/10.1186/1472-6963-14-400

Yesilada, F., \& Direktor, E. (2010). Health care service quality: A comparison of public and private hospital. African Journal of Business Management, 4(6), 962-971.

Neuhauser, D. (2002). Ernest Amory Codman MD. In quality \& safety in health care (Vol. 11, pp. 104-105). https://doi.org/10.1136/qhc.11.1.104 Urquhart, L. M., Ker, J. S., \& Rees, C. E. Exploring the influence of context on feedback at medical school: a video-ethnography study. Advances in Health Sciences Education, 2018 23(1), 159-186. https://doi.org/10.1007/s10459-017-9781-2

Littlejohn, S.W. dan Foss, K.A. Theories of Human Communication. Tenth Edition. Waveland Press, Inc. 2011.

Teunissen, P. W. Experience, trajectories, and reifications: an emerging framework of practicebased learning in healthcare workplaces. Advances in Health Sciences Education. 2015 20(4), 843-856. https://doi.org/10.1007/s10459-014-9556-y

Amin, Z. Medical education in Asia: Is it a time for optimism? Annals of the Academy of Medicine Singapore. 2004 33(2), 264-266 